\title{
Obras poéticas domésticas en Internet: Libertad y creatividad'
}

\author{
Homemade Poetic Works on the Internet: Freedom and Creativity
}

\author{
TERESA IRIBARREN \\ Universitat Oberta de Catalunya \\ España \\ tiribarren@uoc.edu
}

(Recibido: 23-11-2015; aceptado: 29-03-2016)

Resumen. Durante siglos la circulación de textos de las literaturas nacionales ha sido gobernada por unas instituciones de poder vinculadas a las élites políticas y culturales. La academia, la institución escolar y los editores han establecido un canon, es decir, una selección de lecturas que todo lector debía conocer. En el orden mundial, el canon también obedece a unas relaciones de poder: las literaturas pertenecientes a países y a lenguas hegemónicas han gozado de una difusión e influencia mucho mayor que las literaturas subalternas. En el actual contexto de Internet las dinámicas tradicionales de circulación de los textos literarios están cambiando gracias al progresivo empoderamiento de creadores y lectores. En nuestro artículo vamos a demostrar cómo nuevas creaciones domésticas, prácticas y actitudes que vinculan poesía y tecnología digital están propiciando una nueva circulación del patrimonio literario y la eclosión de nuevos géneros que configuran unos prometedores escenarios basados en una mayor libertad, riqueza cultural y equidad.

Palabras clave: Literatura nacional; poesía; forma y género literario; Internet; innovación cultural.
Abstract. For centuries the circulation of texts of national literatures has been ruled by power institutions linked to the political and cultural elites. The academy, the school and publishers have established a canon, i.e., a selection of readings that every reader should know. In the world context, the canon also reflects power relations: literatures from hegemonic countries and languages have enjoyed far greater diffusion and influence than subaltern literatures. In the current context of Internet the traditional dynamic of literary texts circulation is changing thanks to the progressive empowerment of creators and readers. In our article we will demonstrate how new homemade creations, practices and attitudes that link poetry and digital technology are leading to a new circulation of literary heritage and the emergence of new genres that make up promising scenarios based on greater freedom, cultural wealth and equity.

Keywords: National literature; poetry; form and literary genre; the internet; cultural innovation.

\footnotetext{
${ }^{1}$ Para citar este artículo: Iribarren, Teresa (2016). Obras poéticas domésticas en Internet: Libertad y creatividad. 


\section{Literatura mundial: nuevas prácticas de circulación de textos}

Como es bien sabido, el canon ha sido una herramienta fundamental en distintos órdenes culturales. En el marco de las instituciones educativas el canon ha permitido establecer un orden disciplinar y prescribir una selección de lecturas de acuerdo con unos modelos de lengua y unos valores, configurando así un imaginario común que se nutre de referencias culturales compartidas. Esta selección de lecturas imprescindibles, que los ciudadanos han leído con la guía de maestros, profesores y académicos a lo largo de múltiples generaciones, ha sido la clave de la transmisión del patrimonio literario.

La práctica de la lectura institucionalizada ha constituido un instrumento básico para la configuración de una identidad tanto para naciones como para comunidades lingǘsticas. Asimismo, en el marco de las relaciones supranacionales, el canon de la literatura mundial, dictado durante siglos en base a unos principios colonialistas por parte de las metrópolis occidentales, ha brindado a los países hegemónicos un mayor poder e influencia cultural con respecto a países no centrales o subalternos. La poca equidad, la lentitud y la actitud abiertamente reacia a la hora de adoptar diferentes parámetros valorativos que atiendan a la diversidad cultural y lingüística perviven hasta nuestros días, a pesar de que estas dinámicas de canonización hayan sido deslegitimadas desde hace decenios sobre todo por parte de los estudios culturales y de la teoría poscolonial.

En el ámbito de los estudios literarios el análisis sobre el canon continúa ocupando un lugar preeminente de la discusión disciplinar. En el actual contexto de globalización y de circulación de textos literarios en Internet se está prestando especial interés en identificar nuevas dinámicas que están emergiendo en relación con el canon. De acuerdo con el análisis de Damrosch (2006), hoy estaríamos ya en una edad poscanónica. Según su análisis, de los tres estratos en que se jerarquiza el canon, los grandes escritores estarían adquiriendo aún una mayor magnitud (Shakespeare, Cervantes), mientras que paralelamente estarían emergiendo con fuerza los autores subalternos, en detrimento de los considerados autores menores, que pierden visibilidad. Por su parte, Tabbi (2010) valora positivamente que el canon esté experimentando una mayor obertura, que haya una eclosión de creatividad formal y que el sistema literario global esté activo. Sin embargo, lamenta que el elitismo, la hegemonía occidental y el dominio masculino continúen lastrando la literatura mundial.

Internet y la digitalización, ciertamente, están propiciando un escenario inédito en cuanto a la circulación global de los textos. Si cuando vio la luz la primera edición de la Norton Anthology of World Masterpieces (1956) los setenta y tres autores presentados pertenecían en su totalidad a la tradición occidental y eran hombres (hasta la tercera edición, de 1976, no se incluyó una sola mujer, la poeta Safo, y fue sólo a partir de 1990 que se corrigió el predominio de europeos y norteamericanos) (Damrosh 2006), hoy cualquier internauta puede fácilmente acceder a creaciones de figuras absolutamente subalternas, sin mediación de poderes institucionales ni de la industria del libro. 
Ciertamente; una simple búsqueda en Internet nos permite conocer la obra de una figura tan subalterna como es Amal Kassir: mujer, joven, musulmana, americano-siriana y poeta. Si los lectores de la primera edición de la Norton Anthology of World Masterpieces tuvieron que esperar veinte años para descubrir la obra poética de una mujer (de la antiquísima tradición clásica occidental), ahora, mediante una rápida interactuación de la yema del índice sobre la interfaz de una pantalla táctil, fácilmente y con pocos segundos podemos localizar y disponernos a visualizar interpretaciones en varios recitales a los que ha asistido Amal Kassir, celebrados en distintos puntos geográficos, salvaguardados y difundidos a menudo por parte de amateurs en forma de vídeo en plataformas 2.0. Estas prácticas llevadas a cabo con el fin de compartir experiencias literarias altruistamente en Internet sin ninguna duda están propiciando unos nuevos canales de circulación textual. Estos canales activados por múltiples internautas, desligados de las élites culturales, imprimen un dinamismo mucho mayor a la publicación y a circulación de las obras que no los medios de producción y los canales del libro impreso, que tradicionalmente han sido monopolizados por la industria editorial.

La difusión de artefactos poéticos en la Red gracias a la creatividad y a la generosidad de amateurs puede impactar en la configuración del canon literario en los próximos decenios. Difundir la obra poética de Amal Kassir a través de redes sociales, por ejemplo, contribuye a que Internet albergue un corpus literario mundial un poco menos elitista, menos masculinizado y más representativo de producciones no occidentales. Además, piezas con un discurso tan reivindicativo y políticamente comprometido con la condición de la mujer como el que vehicula el poema "This is for the ladies", que sería prohibido en varios países, está accesible en Youtube en grabaciones que recogen un par de vehementes actuaciones de Kassir en recitales (en el Verse Converse Poetry Festival, Taos, publicado el 6 de junio de 2012; en el Mercury Café, Denver, publicado el 24 de junio de 2012). Youtube permite a la poeta y a los internautas poder ejercer el derecho de la libertad de expresión, sin ningún tipo de censura. Según el contador de la red social, a principios de marzo de 2016 los dos vídeos del beligerante discurso en pro de la toma de conciencia por parte de las mujeres, interpretado por una adolescente musulmana, suman ya más de de 130.000 visualizaciones.

\section{Creaciones poéticas digitales domésticas: escritura y lectura}

La gran variedad de nuevas creaciones multidisciplinares que están emergiendo en Internet, accesibles en línea gracias al hormiguero de actividad desarrollada diariamente por millones de usuarios que las comparten sin perseguir fines comerciales, está dibujando un nuevo mapa global de contenidos digitales. Dada la magnitud del cambio de paradigma que suponen las múltiples formas de creación y de difusión de contenidos culturales que se dan en la Red, sin contrapartida económica por parte de lo que se ha convenido en llamar prosumidor, varios autores postulan sustituir el concepto de econo- 
mía de la cultura por el concepto de ecología de la cultura (Holden 2015). De acuerdo con este concepto, la cultura se inscribe en tres esferas a menudo interrelacionadas: la cultura pública, la cultura comercial y la cultura doméstica.

Una de las manifestaciones de cultura doméstica más populares en Internet es la que moviliza las innovaciones tecnológicas para la difusión y el disfrute colectivo del patrimonio textual y de creaciones literarias nativas digitales. En la red los internautas hacen público todo género de escrituras literarias, desde poemas hasta fan-fiction, pasando por blogs literarios, intervenciones de booktubers, blognovelas o tuiteratura (Escandell 2014). Y, paralelamente, también comparten experiencias de lectura, sea en forma de post crítico, de plasmación de impresiones lectoras en cualquier red social, de vídeos de interpretaciones teatrales o de recitales poéticos, o de videopoemas que reinterpretan textos canónicos o que constituyen creaciones propias, entre otras variedades creativas.

Esta amplia tipología de creaciones inmateriales, desarrolladas mayormente al margen de la industria del libro, suelen perseguir recompensas emocionales vinculadas a los visionados y a las respuestas de los internautas, que redundan en una densificación de gratificantes relaciones virtuales entre usuarios. Dado que son concebidas al margen de las leyes del mercado y no hay riesgo de inversión de capital por parte de un empresario, las obras digitales domésticas suelen ser más proclives a sacar partido de la libertad creativa que brindan las herramientas gratuitas disponibles en Internet.

La poesía, el género literario tradicionalmente vinculado a la musicalidad, la imagen, la brevedad y la experimentación formal, encuentra en el medio digital un espacio de fecundación idóneo, porque estos elementos creativos son los propios de la Red. De la amplia variedad de piezas digitales fruto de la imbricación entre poesía y distintas disciplinas artísticas (fotografía, cine, videoarte, música) y el lenguaje informático, destacan especialmente por su innovación formal y libertad creativa los videopoemas y los blogs de experimentación poética. La libertad creativa de estas piezas contrasta con las aplicaciones de creación poética, vinculadas a corporaciones transnacionales e inscritas en programas exclusivos y propietarios, que monitorizan la composición.

\section{Videopoesía}

La videopoesía (o poesía fílmica) es una forma artística cada vez más popular: en la actualidad existen ya en torno a quince festivales dedicados a esta forma creativa. Plataformas como Youtube, Vimeo y blogs de creadores de distintos ámbitos disciplinares acogen videopoemas publicados por amateurs o por videoartistas o cineastas profesionales. La progresiva consolidación del género merece cada vez más atención por parte de la academia, sobre todo a partir de la publicación de Videopoetry, A Manifesto de Tom Konyves (2011). Prueba de este creciente interés es la publicación, a principios de 2016, de la primera revista consagrada a esta forma expresiva: Poetryfilm Magazine. 
La videopoesía es una expresión literaria digital basada a menudo en el apropiacionismo y la remezcla de contenidos que otros creadores hacen circular en Internet bajo licencias Creative Commons (Lessig 2008). Los videos constituyen la ilustración en imágenes y música de un discurso poético bien del patrimonio literario, bien de creación textual propia. La calidad de las creaciones radica en hacer una buena interpretación del texto poético y que el uso de innovaciones tecnológicas redunde en un atractivo discurso multimedia, que busca una efectiva complementariedad de lo visual y lo audible. El creador persigue construir la poeticidad apelando múltiples sensibilidades del internauta que visiona la breve filmación. Videopoemas de buena calidad pueden ser visionados en el portal personal de Sigrun Höllrigl, en los portales colectivos Moving Poems. The best poetry videos on the web, Video Haiku y el gallego Versogramas, en el canal de video de Marc Neys y en el blog del poeta de Castelló de la Plana Josep Porcar.

La imbricación de un discurso visual, verbal y a menudo también musical imprime una densidad retórica a la creación, especialmente cuando el poema es recitado por el propio autor. La seducción suele orquestarse mediante la emocionalidad de las imágenes y acorde con la música y la creación de una atmosfera determinada. Sin ninguna duda, los videopoemas proporcionan nuevas experiencias literarias que responden a las expectativas de unos internautas cada vez más habituados a consumir contenidos culturales breves en línea, preferentemente multimedia.

\section{Experimentación poética en línea: el caso de François Bon y de Philippe De Jonckheere}

Siguiendo la estela experimental de la poesía electrónica (e-poetry) o ciberpoesía $^{2}$, que nació hace años vinculada a grandes empresas informáticas y que se desarrolló en el marco de unos programas propietarios y sus dispositivos asociados (Emerson 2014), hoy algunos escritores publican sus obras en blogs y portales que constituyen un interesante campo de creación de vanguardia. Le Tiers Livre, de François Bon, y Désordre, de Philippe De Jonckheere, constituyen ejemplos paradigmáticos de experimentación poética en línea (Audet y Brousseau 2011), ajena a los intereses económicos de editoriales y de las grandes corporaciones de Internet.

Lejos de los marcos formales de las creaciones poéticas vinculadas al libro impreso, estos espacios creativos personales presentan unas obras dinámicas, alejadas de la idea de finitud, que obedecen a la lógica digital de la combinación. Los portales de Bon y de De Jonckheere son la viva representación cinemática del caos, de la reticularidad. Se sitúan a las antípodas del orden del libro que durante siglos ha sido la base del sistema literario, pero también de determinadas lógicas que rigen Internet: para navegar por los distintos contenidos de los sitios de los creadores no existen motores de búsqueda.

${ }^{2}$ La voz “Ciberpoesía” de Wikipedia define diferentes tipologías de poesía experimental en línea y recoge una muestra representativa de ejemplos del género. 
Se persigue, claramente, la voluntad de desorientar el internauta entre la acumulación de archivos: no existe una cronología, se apuesta por la modularidad y la variabilidad de contenidos, y la obra se reactiva periódicamente con nuevas aportaciones para evitar su fosilización. Los portales de Bon y de De Jonckheere son, pues, una muestra bien representativa de libertad poética otorgada, en este caso, por las posibilidades que brinda la programación informática.

\section{Aplicaciones: ¿imaginación y creatividad coartadas?}

La programación informática es también la clave de aplicaciones de creación literaria que han emergido con fuerza en el espacio digital estos últimos años. Estas aplicaciones tienen como finalidad estimular los usuarios a ser creadores de textos literarios facilitando herramientas intuitivas y atractivas. Una de las aplicaciones de creación poética es $K u$, concebida como red social para componer y compartir haikus. Los usuarios de iOS y de Android $^{3}$ pueden descargarse esta aplicación gratuitamente.

Es especialmente interesante analizar la presentación de esta app que se publicó el 24 de junio de 2013 en el portal Anatomiapp. El post contiene las siguientes indicaciones:

Pero vamos a lo que importa, los haikus! Escribir con Ku es muy sencillo, tenemos una opción guiada, en la que nos mostrará diferentes situaciones y nosotros tenemos que añadir las palabras, como por ejemplo ¿Donde te encuentras ahora? Interesante para escribir sin necesidad de pensar en un tema concreto. Y después tenemos una opción de texto libre, en la que tendremos que rellenar los versos con el tema que nos apetezca. En las dos opciones tenemos la posibilidad de ver cuantas palabras nos quedan y podemos añadir una fotografía para darle más sentido al haiku. (Lavins 2013)

En el portal de Google Play actualmente se presenta la aplicación Ku como "red social creativa”. También es interesante analizar el texto promocional:

Sigue a otros escritores creativos y obtén notas divertidas, interesantes e inspiradoras. Alimenta tu creatividad con Ku!

Expresa tus momentos y pensamientos con palabras y garabatos en una hermosa nota.

Ku le permite:

- Escribe tu momento en una nota de 3 líneas llamada "ku"

\footnotetext{
${ }^{3}$ http://www.kuapp.me/
} 
- Dibuja y añade un garabato a tu ku!

- Personaliza tu "ku" añadiendo una foto

- Lee, me gusta y comenta sobre "kus" de otros usuarios

- Inspírate al instante con nuestra ruta de escritura guiada

- Comparte los "kus" que te gustan en Facebook, Twittery Tumblr

- Sé parte de nuestra creciente comunidad vibrante

- Añade sonido a tu ku!

- Y mucho más...

Un simple ejercicio comparativo de cómo se instrumentaliza la programación informática en los portales en línea de Bon y de De Jonckheere y en una aplicación como $K u$ nos permite afirmar que la libertad poética es mucho mayor en el caso de los primeros. Las aplicaciones vinculadas a las grandes corporaciones de Internet se presentan como un verdadero estímulo de creatividad personal, que invita al lector de poesía a convertirse en poeta mediante un uso lúdico y fácil de un desarrollo creativo preprogramado. Pero a nadie debería escapar que la imaginación se ve coartada por unas pautas que monitoriza el programa informático propietario. No es ocioso señalar que este programa ha sido diseñado por una empresa tecnológica que busca recompensas económicas - con todos los derechos reservados, según consta en su portal. Sería ciertamente interesante indagar si los usuarios que publican a través de sus redes sociales creaciones poéticas domésticas desarrolladas en aplicaciones como Ku son conscientes de la monitorización de su libertad expresiva.

\section{Conclusiones}

En la actual ecología de la cultura, el uso extensivo de herramientas digitales gratuitas en Internet y de las redes sociales está densificando la circulación de una amplia variedad de géneros poéticos digitales de naturaleza doméstica. A través de varios ejemplos hemos podido comprobar que la escritura, la lectura, la interpretación y el visionado de estas obras confieren a los sistemas literarios que convergen en la Red un mayor grado de libertad de expresión y de libertad formal. En contraste, las piezas desarrolladas en el marco de las aplicaciones de creación literaria, por el hecho de estar monitorizadas por un programa propietario que marca unos parámetros que coartan la creatividad, gozan de una menor capacidad de experimentación y de libertad expresiva.

Las creaciones poéticas que los internautas comparten generosamente en la Red imprimen una nueva vitalidad y dinamismo a la literatura mundial. Este gigantesco corpus global, que crece exponencialmente día a día, se publica en Internet al margen de la lógica capitalista, de los tradicionales poderes de las instituciones culturales y de la industria del libro. Si durante siglos las instituciones de cultura y los editores han seleccio- 
nado lo que se debía publicar y, por tanto, sancionaban lo que el ciudadano podía leer de acuerdo con los valores de estas élites, hoy las cosas están cambiando radicalmente. Este cambio, protagonizado por la inquietud creativa de multitud de usuarios, está generando ya fisuras en la dinámica tradicional de los sistemas literarios. Los usuarios de Internet acceden a textos en otras lenguas, de tradiciones literarias tanto cercanas como lejanas, que vehiculan valores, referentes e imágenes que pueden pertenecer o no a su universo cultural. Estos textos establecen una atractiva y fecunda relación con otras disciplinas y artes en el espacio digital. Además, tienen la virtud de ser fácilmente accesibles para un público lector potencialmente enorme, por un lado, y de poder establecer vínculos intertextuales con otros contenidos, por el otro. Esta nueva reticularidad de los contenidos textuales está empezando a configurar una cartografía inédita en la historia de la literatura mundial. Una literatura mundial que, en el espacio digital, poco a poco se está emancipando de los dictados del mercado.

Frente a este escenario, los profesores y académicos, como agentes clave en la transmisión y revisión del canon y en el descubrimiento de nuevos valores literarios, deberíamos considerar críticamente este corpus digital doméstico, a pesar de que sea caótico, de dimensión oceánica y sumamente irregular desde el punto de vista cualitativo. Una labor de identificación de artefactos con valor poético permitiría instrumentalizar estas creaciones domésticas en beneficio de la formación literaria del alumnado. La lectura y visualización de este corpus, más allá de que pueda ser un atractivo estímulo para trabajar en el aula el lenguaje poético y reforzar la comprensión crítica de la cultura digital, puede contribuir a incorporar nuevos paradigmas de canonización. Invitar a los alumnos a visionar interpretaciones como las de la adolescente musulmana Amal Kassir, que contempla la creación poética como un esperanzador instrumento para transformar la sociedad, no sólo puede corregir los lastres de las concepciones canónicas tradicionales y contribuir a forjar una concepción de la literatura mundial que abandere la libertad de expresión, la libertad creativa, la riqueza cultural y la equidad. También puede propiciar el reconocimiento y la comprensión de distintas identidades, lenguas, religiones y sensibilidades culturales en nuestra civilización global. 


\section{Bibliografía}

- Audet, René; Simon Brousseau (2011). Pour une poétique de la diffraction de l'oeuvre numérique. L'archive, le texte et l'oeuvre à l'estompe. Protée, 39 (1): 9-22.

- Damrosch, David (2006). World Literature in a Postcanonical, Hypercanonical Age. En Haun Saussy (ed.). Comparative Literature in an Age of Globalization (pp. 43-53). Baltimore: The Johns Hopkins University Press.

- Emerson, Lori (2014). Reading Writing Interfaces. From the Digital to the Bookbound. Minneapolis, London: University of Minnesota Press.

- Escandell, Daniel (2014). Tuiteratura: la frontera de la microliteratura en el espacio digital.Iberic@l, 5: 37-48.

- Holden, John (2015). The Ecology of Culture. A Report commissioned by the Arts and Humanities Research Council's Cultural Value Project. Arts and Humanities Research Council: Swindon.

- Konyves, Tom (2011). Videopoetry: A Manifesto. Obtenido el 28 de febrero de 2016 desde http://issuu.com/tomkonyves/docs/manifesto_pdf

- Lessig, Lawrence (2008). Remix. Making Art and Commerce Thrive in the Hybrid Economy. London: Bloomsbury.

- Tabbi, Joseph (2010). Electronic Literature as World Literature; or, The Universality of Writing under Constraint. Poetics Today, 31 (1): 17-50.

\section{Sitios web citados}

- Bon, François (2016). Le Tiers Livre. Obtenido el 28 de febrero de 2016 desde http:// www.tierslivre.net/

- Ciberpoesía (2016). Obtenido el 28 de febrero de 2016 desde https://es.wikipedia. org/wiki/Ciberpoes\%C3\%ADa

- De Jonckheere, Philippe (2016). Desordre.net. Obtenido el 28 de febrero de 2016 desde http://desordre.net/

- Höllrigl, Sigrun (2016). Artist biography. Obtenido el 28 de febrero de 2016 desde http://sigrunhoellrigl.net/ 
- Lavins, Fer (24 junio 2013). Ku, red social para compartir haikus. Anatomiapp. Obtenido el 28 de febrero de 2016 desde http://www.anatomiapp.es/2013/06/heyku-redsocial-para-compartir-haikus.html

- Mark Neys (aka Swoon)'s Videos (2016). Obtenido el 28 de febrero de 2016 desde https://vimeo.com/swoon/videos

- Moving poems. The best poetry videos on the web (2016). Obtenido el 28 de febrero de 2016 desde http://movingpoems.com/

- Ku (2016). Obtenido el 28 de febrero de 2016 desde http://www.kuapp.me/

- Google Play (2016). Ku, red social creativa. Obtenido el 28 de febrero de 2016 desde https://play.google.com/store/apps/details?id=com.heyku.android\&hl=es_419

- Porcar, Josep (2016). Salms. Obtenido el 28 de febrero de 2016 desde http://www. porcar.net/

- Versogramas (2016). Obtenido el 28 de febrero de 2016 desde http://versogramas. $\mathrm{com} / \mathrm{es} /$

- Video Haiku (2016). Obtenido el 28 de febrero de 2016 desde https://vimeo.com/ channels/vidhaiku 